\title{
Sustainable sediment management options for reservoirs: a case study of Chashma Reservoir in Pakistan
}

\author{
Mubashar Ali ${ }^{1}\left[\right.$. Abdul Sattar Shakir ${ }^{2}$
}

Received: 16 October 2017 / Accepted: 12 June 2018 / Published online: 19 June 2018

(c) The Author(s) 2018

\begin{abstract}
Globally the average annual loss of reservoir capacity is approximately $1 \%$. Pakistan is confronting major issue of sedimentation which is continuously depleting the useful storage of reservoirs. GSTARS3 model was used to determine the rate of deposition and sediment pattern of Chashma Reservoir since its operation. The model was calibrated and validated for bathymetric survey of 2008 and 2012. The results of GSTARS3 were incorporated to a GIS software to visualize sediment accumulation in reservoir. The study reveals that sediment flushing of the Chashma Reservoir can be carried out during flood season at a pond level of $638.15 \mathrm{ft}$. (194.51 m). However, its negative impact if any on the hydropower generation needs to be analysed. Accordingly, modified operation rules would be required.
\end{abstract}

Keywords Sedimentation · Bathymetric survey $\cdot$ GSTARS3 $\cdot$ Sediment accumulation $\cdot$ Flushing $\cdot$ Operational rules

\section{Introduction}

Sedimentation in reservoirs is an outcome of constructing an obstruction in a flowing river, which results in an abatement of the transport capacity of river. The capacity of reservoir diminishes due to silt aggregation and altered sediment balance due to erosion of river downstream. Reservoir sedimentation represents a serious threat to the storage available. Globally, the annual loss rates relative to installed capacity are generally estimated to range between 0.5 and 1\% (Mahmood 1987; White 2001; Basson 2009; Schleiss et al. 2010). Pakistan is confronting major issue of sedimentation which is continuously depleting the useful storage of reservoirs. Indus river system has three reservoirs, i.e. Chahsma, Tarbela and Mangla. As per hydrographic survey of 2011-2012, reservoir capacities of Chashma and Terbella have reduced to 60 and 35\% of gross storage capacity. Whereas the reservoir capacity for Mangla Reservoir after

Mubashar Ali

muhammad.mubashar2006@gmail.com

Abdul Sattar Shakir

shakir@uet.edu.pk

1 Water Resource Management, Flood Risk Assessment Unit, Punjab Irrigation Department, Lahore, Pakistan

2 Faculty of Civil Engineering, University of Engineering and Technology, Lahore, Pakistan raising of Mangla dam has been reduced to $1 \%$ of gross storage capacity (Pakistan Water and Power Development Authority 2012). All reservoirs trap a portion of the sediment load carried by inflows and, therefore, will experience a continuous reduction in storage volume. The sediment deposition has unfavourable impact, for example, increase in back water level, formation of shoals. Due to the increase in sedimentation flow, regulation diminishes and eventually the reservoir could not achieve its objectives like irrigation, flood mitigation and hydropower generation etc. For a sustainable use of reservoir, it will be necessary to regulate the flows and effective sediment management should be carried out. Since the last few years number of numerical models have been developed and utilized to investigate the reservoir sedimentation problems in rivers and natural streams. Zeleke et al., (2013) used SRH-1D model to predict the sediment inflow to Angereb dam reservoir. The simulation results were in good agreement with the measured sediment deposition in the reservoir. One-dimensional numerical model GSTARS-3 developed by Yang and Simoes (2002) based on theory of minimum stream power has some additional features that it can be applied for determination of channel width while keeping depth as a known parameter for given hydraulic and sediment routing conditions.

Yang and Simoes (2002) applied GSTARS-3 model for simulation of sedimentation and delta movement in Terbela Reservoir in Pakistan. The profile of the bed simulated 
using GSTARS-3 was in good agreement with the measured profile. In the present study, GSTARS-3 (Generalized Sediment Transport for Alluvial Ricers) sediment transport model along with GIS software was used to determine (1) sediment inflow to Chashma Reservoir, (2) sediment pattern and rate of deposition in the Chashma Reservoir and (3) to explore the ways to enhance the life of reservoir based on various operational scenarios for sediment management.

\section{Location of the study area}

The Chashma Barrage is situated on the Indus River at a distance of $56 \mathrm{~km}$ from Jinnah Barrage. The barrage supplies water to the Chashma Jhelum Link (CJ Link) Canal on the left bank and Chashma Right Bank Canal (CRBC) on the right bank. Chashma Barrage has shallow reservoir with some storage component, original gross storage capacity of the reservoir was $0.87 \mathrm{MAF}(1.073 \mathrm{BCM})$ with live and dead storage of $0.72 \mathrm{MAF}(0.888 \mathrm{BCM})$ and 0.15 MAF (0.185 BCM), respectively. Five hydrographic surveys of Chashma Reservoir were carried out since the operation of reservoir started. The hydrographic surveys of Chashma Reservoir revealed that capacity of the reservoir is depleting vigorously due to sediment deposition. Location plan of Chashma Reservoir and reduction in reservoir capacity are shown in Fig. 1. The maximum and minimum designed reservoir levels are $649 \mathrm{ft}$. $(197.81 \mathrm{~m})$ and $638.15 \mathrm{ft}$. $(194.51 \mathrm{~m})$, respectively. The last hydrographic survey in 2011-2012 showed that the gross capacity depleted to $0.348 \mathrm{MAF}(0.429 \mathrm{BCM})$, live capacity to $0.231 \mathrm{MAF}(0.285 \mathrm{BCM})$ and dead storage as 0.117 MAF (0.144 BCM) (ISRIP-WAPDA). The problem of Chashma Reservoir is that it is indiscriminately being filled up and drawdown several times each year without respect to its response to this treatment. Sand bars developed in front of the barrage in the form of delta. The delta has spread to the barrage like a braided stream. Analysis of hydrographic survey shows that process of bela and active river channels formation has almost stabilized. Growth of weeds and bushes on belas stabilized the sediment layers. Additionally, during low flow season the gates of the barrage are closed to provide water to the hydle power station. Because of this, the water upstream of barrage ponded up and sediments started settling down.

\section{Methodology}

The processes involved in this study include data collection, data analysis and selection of suitable transport model. Calibration of the model is done before hydraulic and sediment routing computation for Chahsma Reservoir. GSTRAS-3 is capable of performing hydraulic and sediment routing computations both in longitudinal and lateral directions. Furthermore, it is also capable

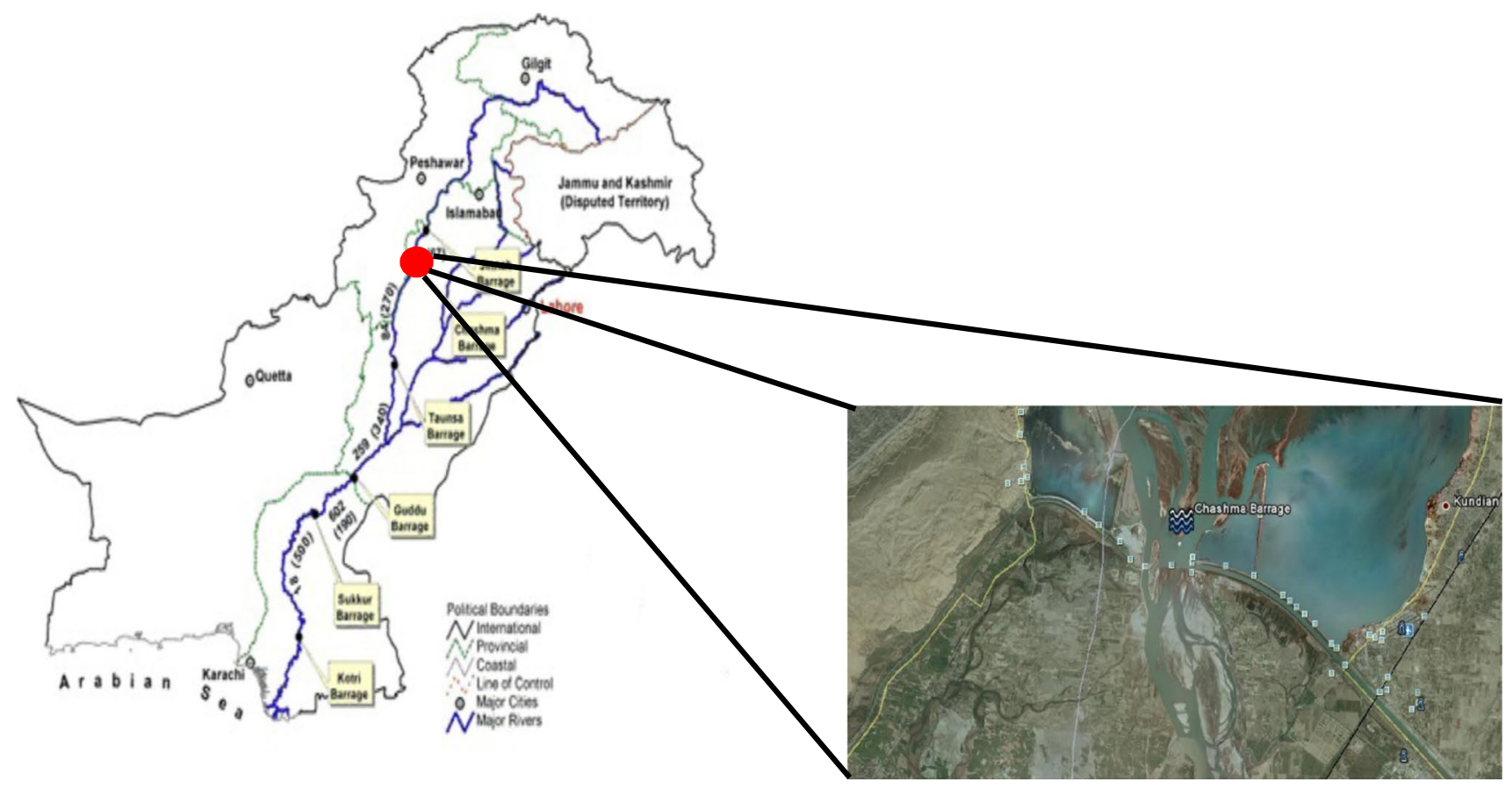

Fig. 1 Location plan of Chashma Barrage 
of computing channel geometry with fixed or movable boundary conditions.

\section{Data collection}

Following necessary data were collected and used for GSTARS3 sediment transport model:

\section{Geometry data}

Cross-sectional geometry was defined by $X-Y$ coordinate which is a lateral location and bed elevation. Lateral locations $(X)$ were given using a reference point for each cross section, and the coordinate pair was entered in order of increasing $X$ coordinate, i.e. starting from the left-hand side of the cross section and marching towards the right-hand side (looking downstream). In this study, 15 cross sections were used to cover entire reservoir for modelling purposes.

\section{Hydrological data}

Hydrological data include water discharges, temperatures and water surface elevations. Daily discharge data for Chashma Barrage for the year 1971-2012 was collected from surface water hydrology project (SWHP), WAPDA. Mean annual flow for Chashma Reservoir is $117,000 \mathrm{ft}^{3} / \mathrm{s}$ (3313 $\left.\mathrm{m}^{3} / \mathrm{s}\right)$ whereas the peak annual discharge is $313,627 \mathrm{ft}^{3} / \mathrm{s}\left(8881 \mathrm{~m}^{3} / \mathrm{s}\right)$. Discharge required for flushing of reservoir should be twice of mean annual flow available. Therefore, flushing of Chahsma Reservoir was performed for an available discharge of 2,340,000 $\mathrm{ft}^{3} / \mathrm{s}\left(6626 \mathrm{~m}^{3} / \mathrm{s}\right)$. Flushing discharge is available during flood season for two months, i.e. July-August.

\section{Sediment data}

Sediment data comprise of bed gradation data and sediment inflow hydrograph. Bed gradation data and suspended sediment load data for D/S of Jinnah Barrage was collected from WAPDA and sediment gradation curve for suspended load was plotted. Particle size distribution at D/S of Jinnah Barrage showed that suspended sediment load comprises of $18 \%$ clay, $75 \%$ silt and $7 \%$ of sand. Sediment inflow to Chahsma Reservoir is specified in terms of sediment rating curve downstream of Jinnah Barrage. The measured suspended sediment load data for the period of 2012-2013 has been used for developing the sediment rating curve which is used as inflow boundary condition at downstream of Jinnah Barrage as shown in Fig. 2.

\section{Calibration of model}

The model was calibrated by simulating the observed sediment deposition from the year 1971 to 2008 . By slightly adjusting the Manning's " $n$ " value and using eight-sediment transport function, a good agreement between measured and simulated values can be found. Figure 3 shows calibration for the Chashma Reservoir thalweg profile using eight-sediment transport function. Out of the eight-sediment transport function, Yang's $(1973+84)$ sediment transport function gave more closer results to actually observed thalweg profiles. Reservoir capacity computed using Yang's 1973+84 sediment transport function is 0.3283 which is $2.28 \%$ more than the actually observed capacity of reservoir in 2008. Figure 4 shows the thalweg profile of reservoir using Yang's $1973+84$ sediment transport function.

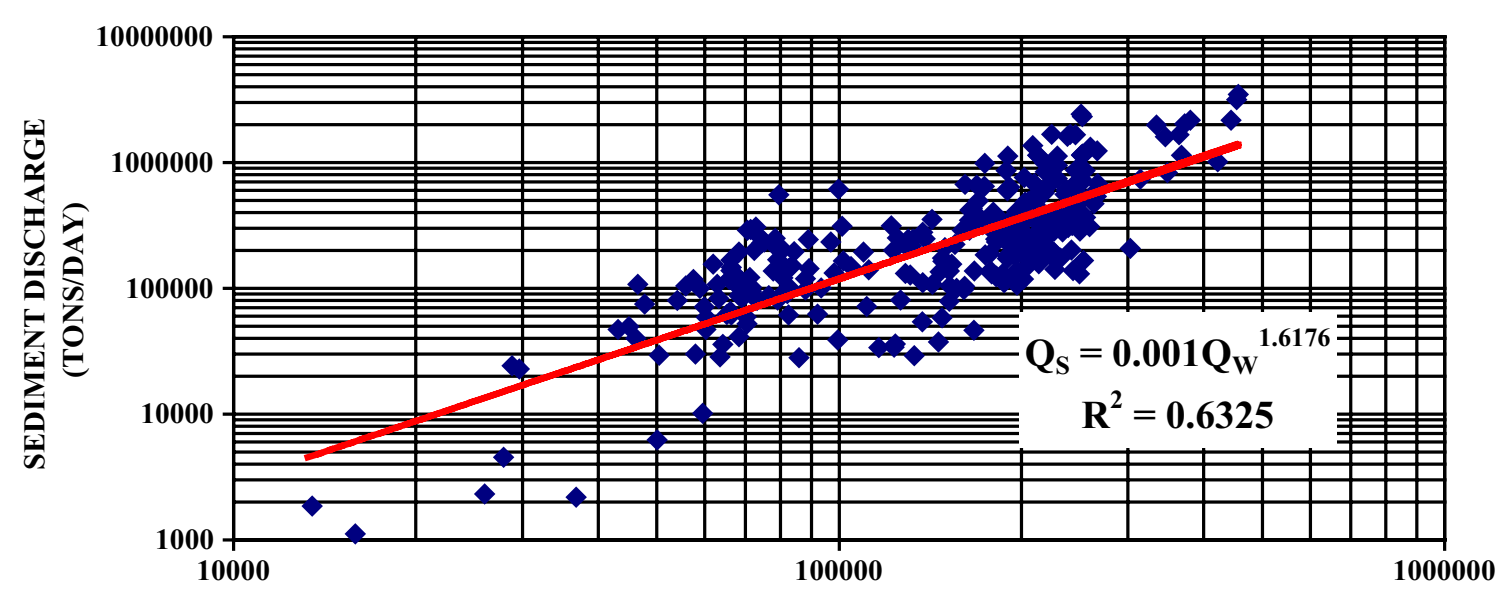

WATER DISCHARGE (CUSECS)

Fig. 2 Sediment rating curve 


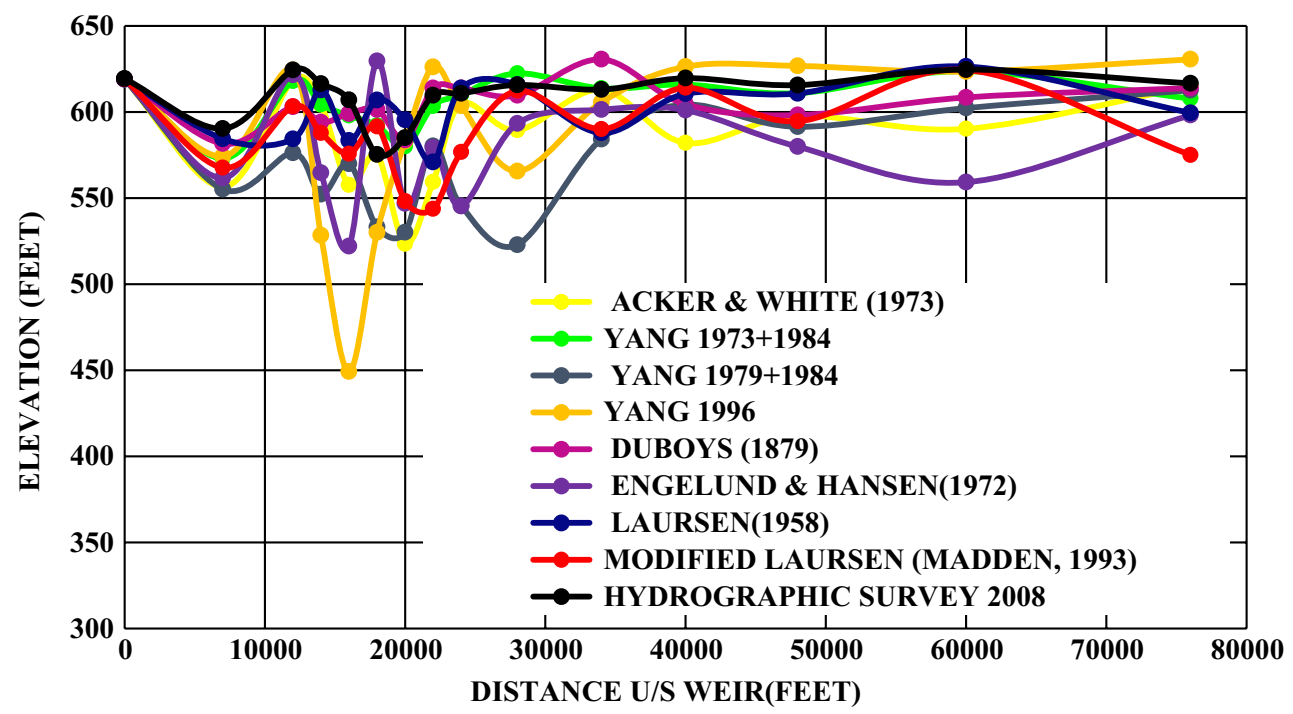

Fig. 3 Performance of various sediment transport functions in estimating the bed levels

Fig. 4 Calibration of the model using Yang's $1973+84$ sediment transport function for the year 1971-2008

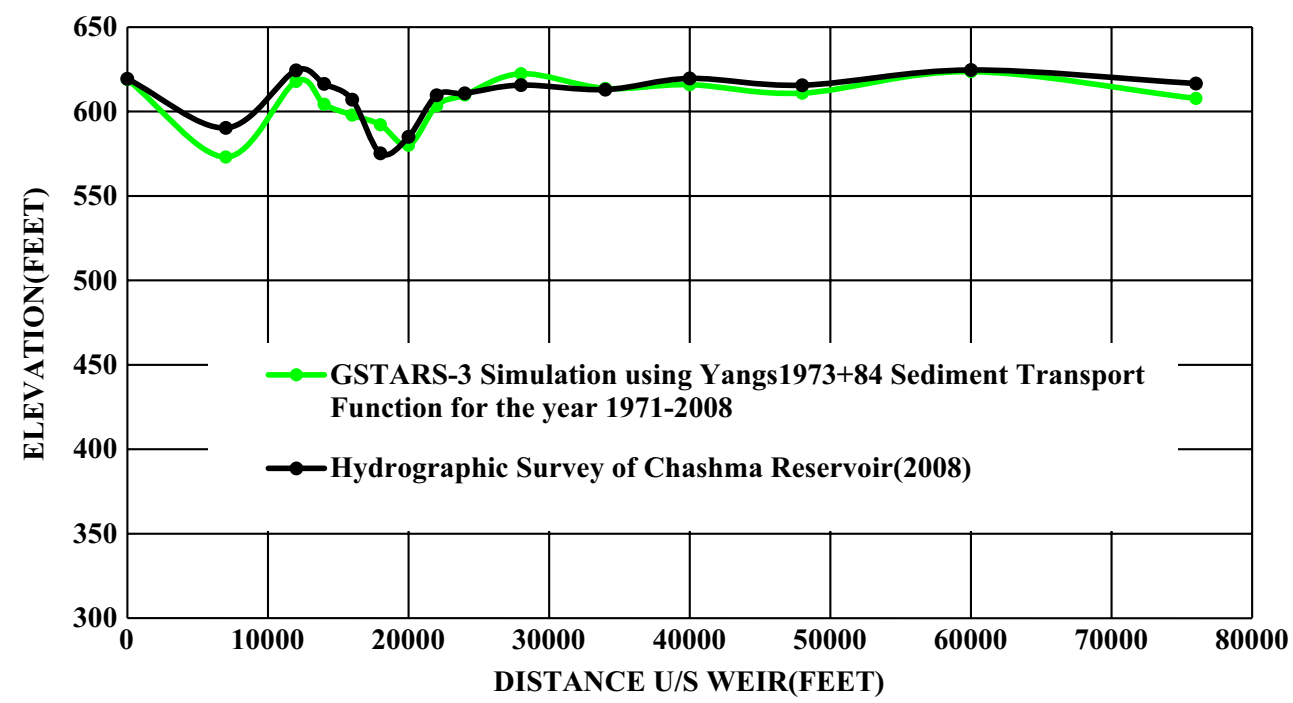

\section{Validation of model}

The validation of model is done to evaluate its performance by using the parameters which were adjusted during calibration process. The validation of model is performed by using the bathymetry data for the year 2008 to 2012 using Yang's $1973+84$ sediment transport function. After simulation, the reservoir capacity computed is $0.321 \mathrm{MAF}$ which is $7.71 \%$ lesser than the capacity computed using hydrographic survey in 2012. Figure 5 shows the validation of Chashma Reservoir.

\section{Results}

After calibration and validation model was applied for future application from 2013 to 2054 for five different operational scenarios. The adjusted GSTARS3 model was applied for 10-, 20- and 42-year simulation period. The results of above five scenarios are as follows:

\section{Scenario-1}

In scenario no. 1, flow and pond level values of the last 42 years were repeated for future prediction of Chashma Reservoir storage capacity. The storage capacity computed for 10,20 and 42 years of simulation was $0.285 \mathrm{MAF}(0.352$ 
Fig. 5 Validation of the model using Yang's $1973+84$ sediment transport function for the year 1971-2008

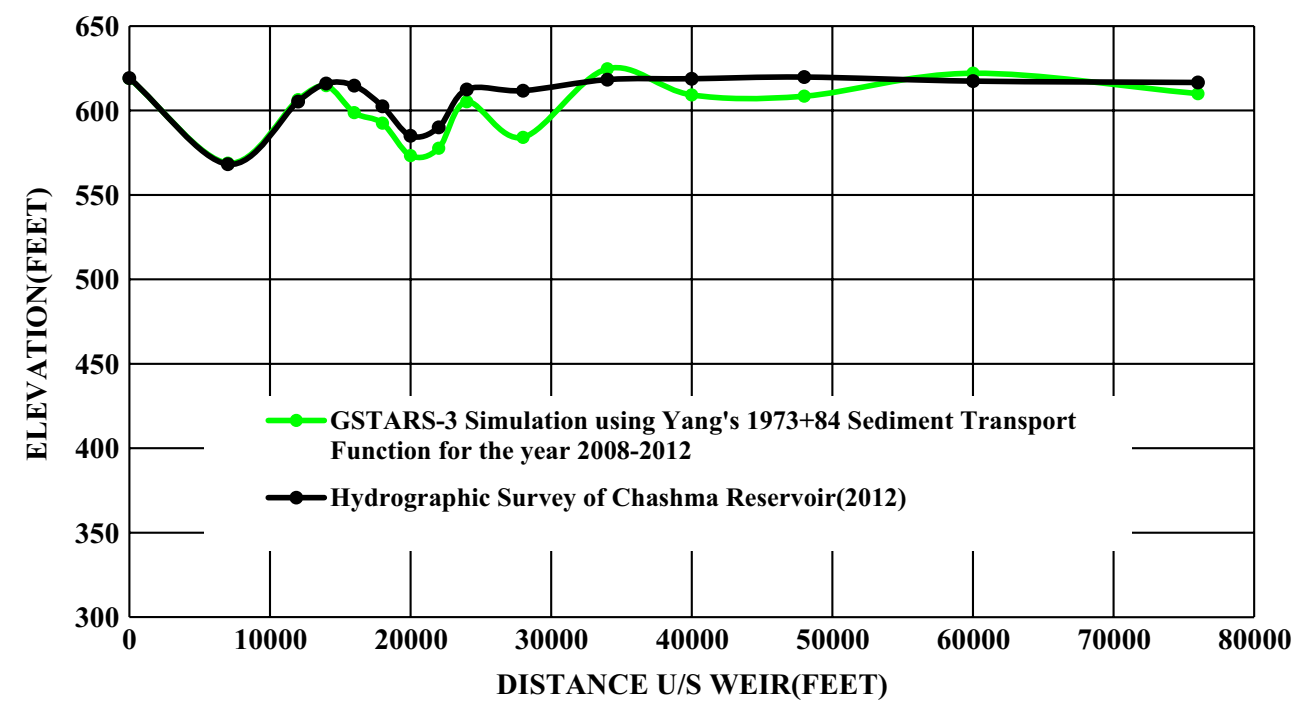

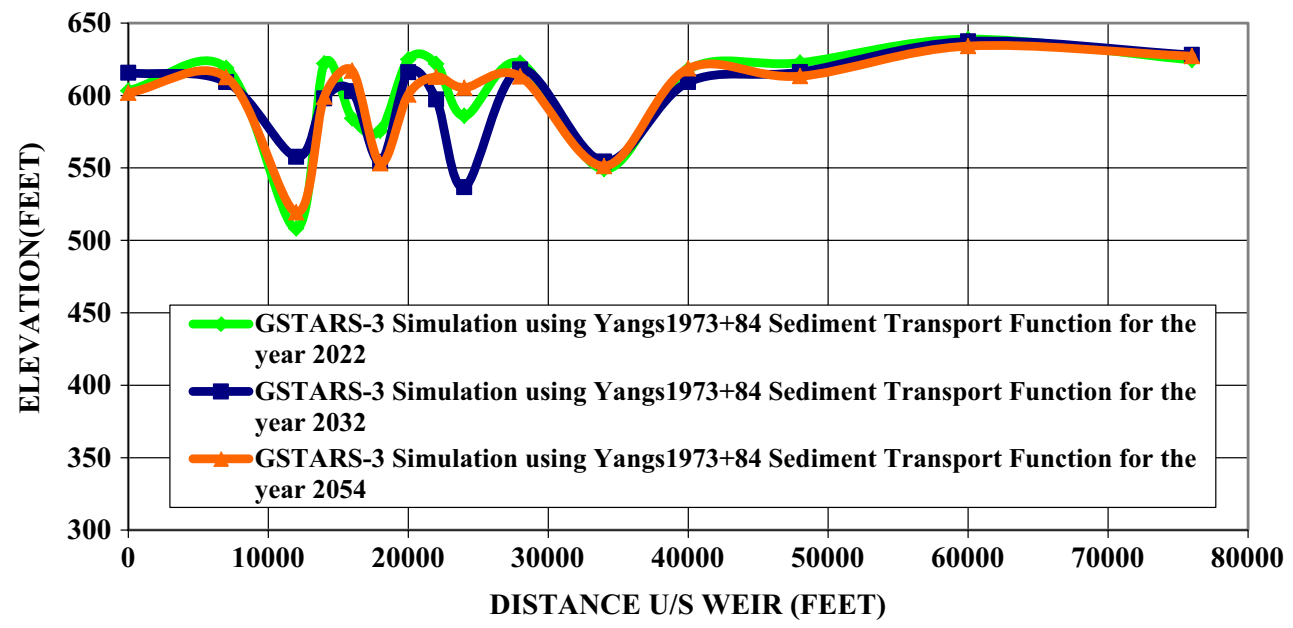

Fig. 6 Simulation results for scenario-1

BCM), 0.264 MAF (0.326 BCM) and 0.233 MAF (0.287 $\mathrm{BCM})$. This showed that the capacity of reservoir would be depleted to $73 \%$ of gross storage capacity after 42 years of simulation. The change in bed elevation for 10, 20 and 42 years of simulation is shown in Fig. 6. However, it is reasonable to compare the GSTARS-3 results with HEC-RAS results for Chashma Reservoir which shows that the capacity of reservoir would be depleted to 0.245 (0.302 BCM) MAF while operating under existing conditions (Shah 2010).

\section{Scenario-2}

In scenario no. 2, flow values of the last 42 years were taken for simulation period. Besides this, pond level was kept at $638.15 \mathrm{ft}$. for 15 days (1st July-15th July) to see the trends for sediment flushing. The storage capacity computed after 10,20 and 42 years of operation was 0.393 MAF $(0.485$
BCM), 0.414 MAF (0.511 BCM) and 0.429 MAF (0.529 $\mathrm{BCM})$. The results of scenario-2 revealed that the capacity of reservoir would recover to $23 \%$ of gross storage capacity after 42 years of operation while considering 15 days flushing. The change in bed elevation and sediment trap efficiency for 10-, 20- and 42-year simulation period is shown in Fig. 7.

\section{Scenario-3}

In scenario no. 3, flow values of the last 42 years were taken for simulation period. Besides this, pond level was kept at $638.15 \mathrm{ft}$. for 30 days (1st July-30th July) to see the trends for sediment flushing. The storage capacity computed after 10,20 and 42 years of operation was $0.435 \mathrm{MAF}(0.537$ $\mathrm{BCM}), 0.440 \mathrm{MAF}(0.543 \mathrm{BCM})$ and $0.476 \mathrm{MAF}(0.587$ $\mathrm{BCM})$. The results of scenario-3 revealed that the capacity of reservoir would recover to $37 \%$ of gross storage capacity 


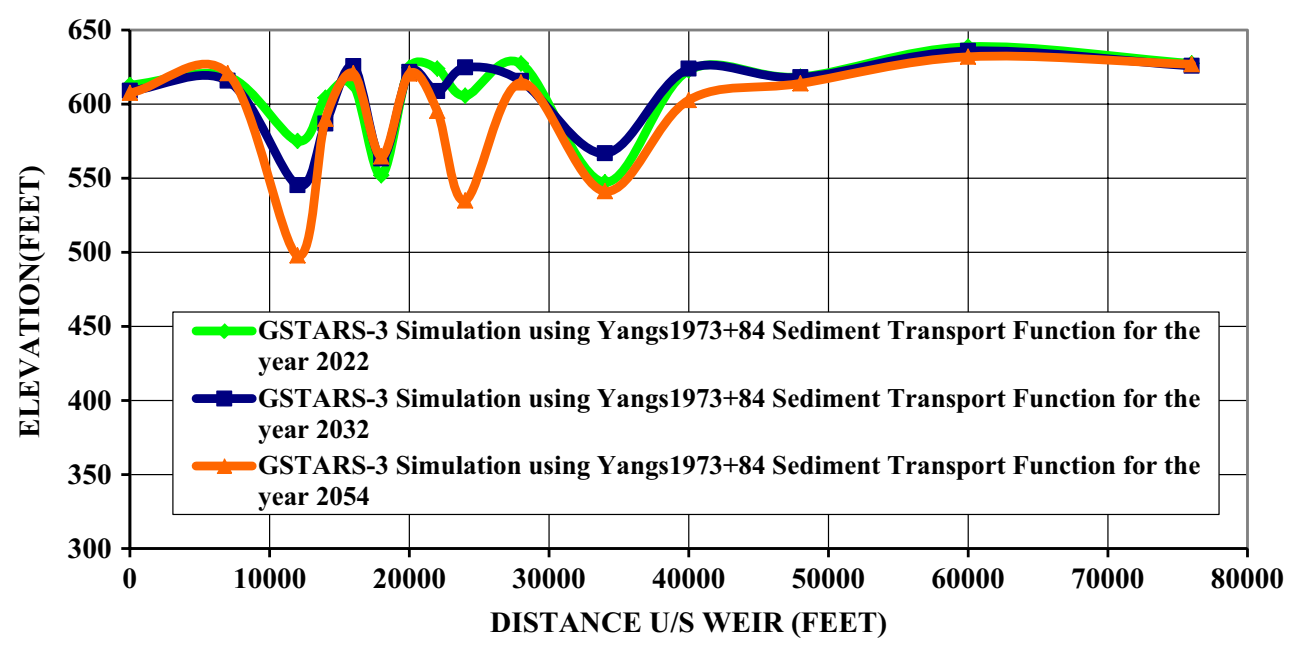

Fig. 7 Simulation results for scenario-2

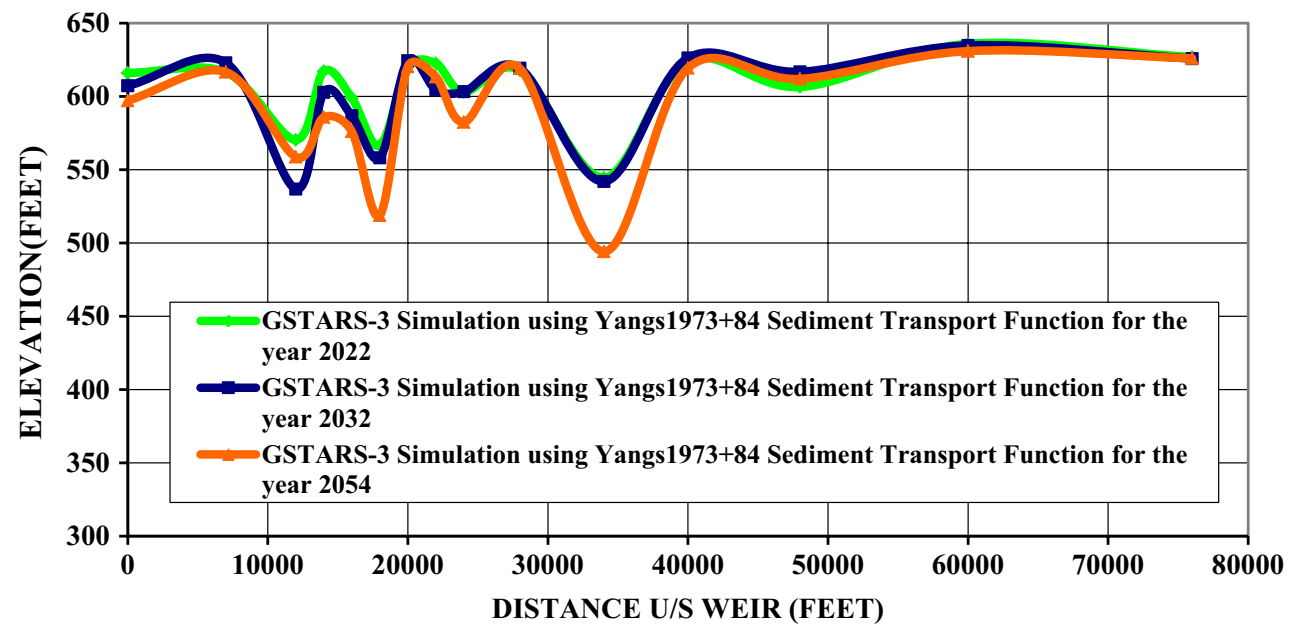

Fig. 8 Simulation results for scenario-3

after 42 years of operation while considering 30-day flushing. The change in bed elevation and sediment trap efficiency for 10-, 20- and 42-year simulation period is shown in Fig. 8.

\section{Scenario-4}

In scenario no. 4 , flow values of the last 42 years were taken for simulation period. Besides this, pond level was kept at $638.15 \mathrm{ft}$. for 45-day flushing (1 st July-15th August) to see the trends. The storage capacity computed after 10,20 and 42 years of operation was $0.501 \mathrm{MAF}$ (0.618 BCM), 0.538 MAF (0.664 BCM) and 0.579 MAF $(0.714 \mathrm{BCM})$. The results of scenario- 4 revealed that the capacity of reservoir would recover to $66 \%$ of gross storage capacity after 42 years of operation while considering 45-day flushing. The change in bed elevation and sediment trap efficiency for 10-, 20- and 42-year simulation period is shown in Fig. 9.

\section{Scenario-5}

In scenario no. 5 , flow values of the last 42 years were taken for simulation period. Besides this, pond level was kept at $638.15 \mathrm{ft}$. for 60 days flushing (July-August) to see the trends. The storage capacity computed after 10, 20 and 42 years of operation was $0.594 \mathrm{MAF}(0.733 \mathrm{BCM}), 0.601$ MAF (0.741 BCM) and 0.644 MAF (0.794 BCM) $(85 \%$ Gross storage capacity). The change in bed elevation and 


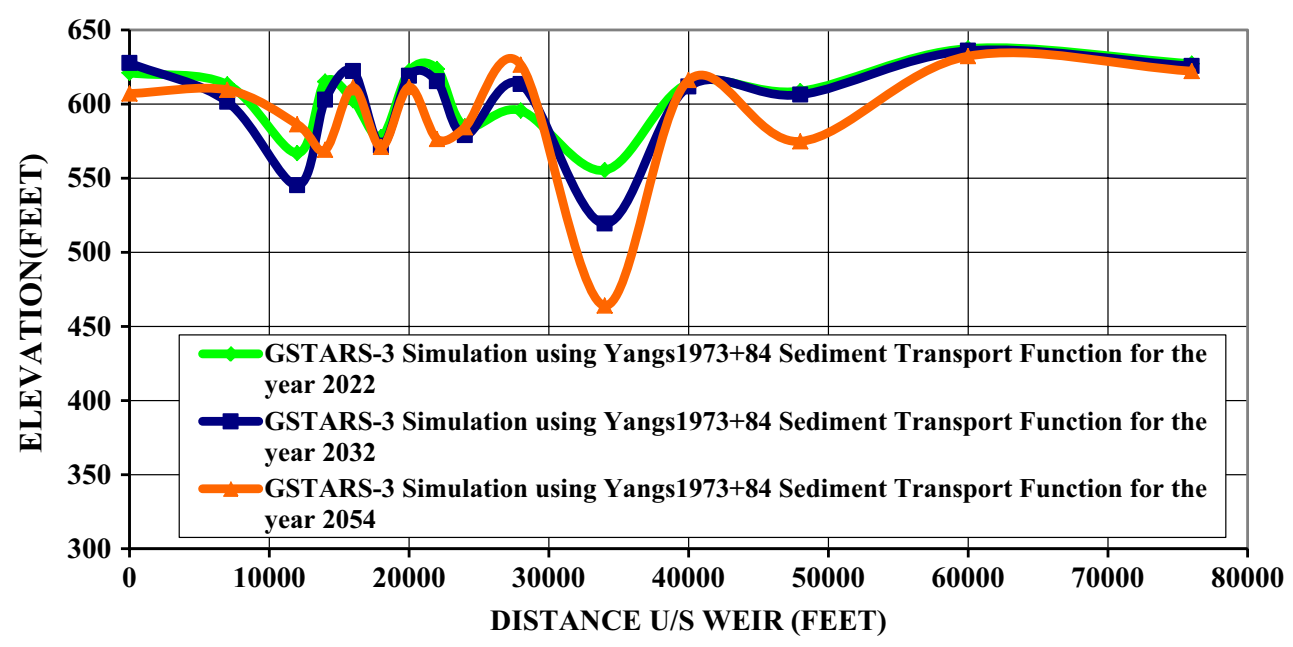

Fig. 9 Simulation results for scenario-4

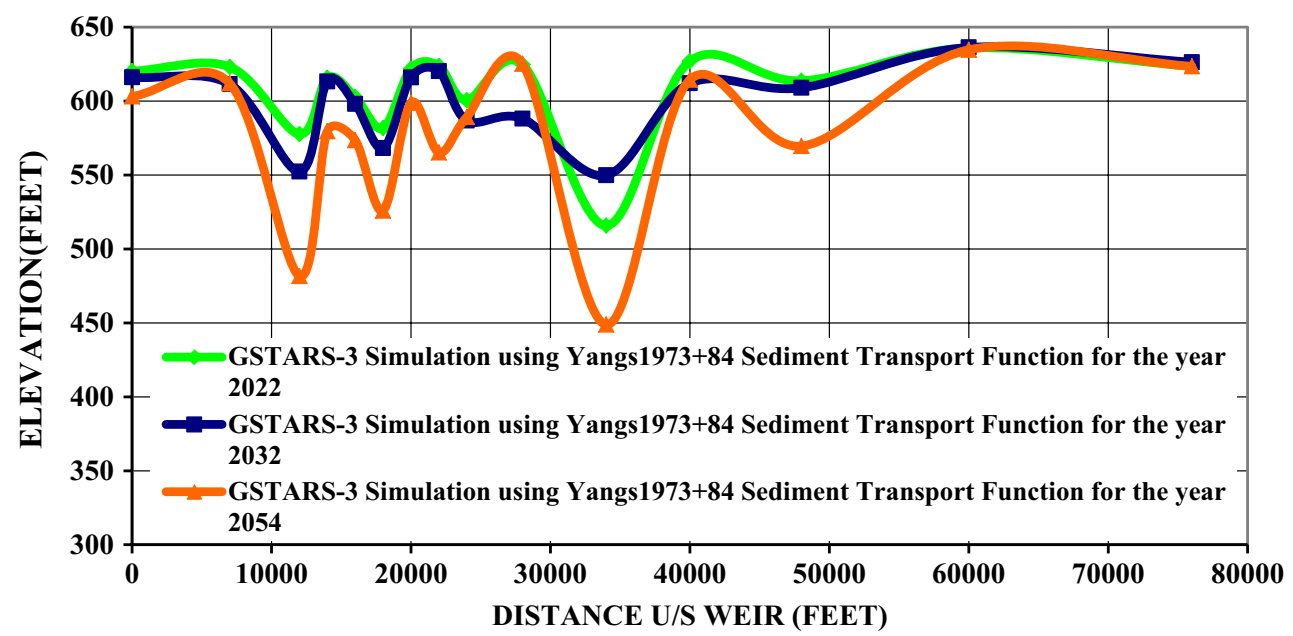

Fig. 10 Simulation results for scenario-5

sediment trap efficiency for 10-, 20- and 42-year simulation period is shown in Fig. 10.

\section{Discussion}

Performance of GSTARS3 sediment transport model was assessed statistically using MAPE, Nash-Sutcliffe efficiency and $R^{2}$. Nash-Sutcliffe efficiency is a statistical tool which is used to compare the simulated results with the actually observed bathymetric survey data. NSE values for calibration and validation of sediment transport model were found as 0.64 and 0.45 with the coefficient of determination 0.67 and 0.70 . The difference between measured and simulated thalweg for calibration and validation of sediment transport model was found as 0.55 and $1.5 \%$. Yang (2008) compared the sediment simulation results of
Tarbela Reservoir with the bathymetric survey in Pakistan and concluded that the error less than $20 \%$ is acceptable between the measured and simulated results.

GSTARS-3 software is capable to determine the amount of sediment accumulated in the reservoir as well as the amount of sediments that exit the river reach. Amount of sediments deposited in the Chashma Reservoir during calibration and validation of model were $9.283 \times 108$ and $9.437 \times 108$ Ton, respectively. However, it is reasonable to compare this with Terbela Reservoir in Pakistan where amount of sediments entered into the reservoir were $1.01 \times 1010$ Ton from 1976 to 1994 . Similarly, the amount of sediments deposited in Tapu Reservoir in Thailand was $2.3 \times 106$ Ton from 1987 to 1990 . Both of these reservoirs were also modelled using GSTARS-3 sediment transport model. 
Table 1 Sediment trap efficiencies

\begin{tabular}{ll}
\hline Scenario & $\begin{array}{l}\text { Sediment trap } \\
\text { efficiency }(\%)\end{array}$ \\
\hline Scenario-1 & $51-58$ \\
Scenario-2 & $43-11$ \\
Scenario-3 & $47-12$ \\
Scenario-4 & $54-15$ \\
Scenario-5 & $65-16$ \\
\hline
\end{tabular}

Sediment trap efficiency was computed for 10-, 20- and 42-year simulation period for all the five scenarios and then compared with Brune curve for normal ponded reservoir as shown in Table 1. Intensive research studies based on field data were carried out in India to verify validity of Brune curve for Matatila, Hirakhud, Bhakra and Gandhi Sagar Reservoirs (Batuca and Jordaan 2000). Brune curve overestimated the trap efficiency for the first two reservoirs.

\section{Integrating GSTARS3 results to GIS software}

The results obtained from GSTARS3 simulation were incorporated to GIS software to visualize sediment accumulation in the reservoir. Delta formation was observed just $1.0 \mathrm{~km}$ from main barrage portion. Therefore, two sections had been selected from fifteen sections where most of the sedimentation took place, i.e. cross section number 1 and cross section number 19. Cross section 1 and cross section 19 exist at a distance of 3 and $8.5 \mathrm{~km}$ from main barrage portion. A digital elevation model (DEM) was generated by combining the geometry output from GSTARS-3 model. Figure $11 \mathrm{a}, \mathrm{b}$ showed the elevation of Chashma Reservoir during calibration and validation of sediment transport model. Figure 11a showed that the elevations of points at section 1 and section 19 in year 2008 range between $620-648 \mathrm{ft}$. (188.97-197.51 m) and 624-644 ft. (190.19-196.29 m). Whereas, for validation elevation of section 1 and section 19 ranges between 613-645 ft. (186.84-196.59 m) and 617-637 ft. (188.06-194.16 m). The bed elevation of Chashma Reservoir for validation was lowered than the calibration results. This is just because of the super flood in 2010. After the super flood of 2010, the capacity of the Chashma Reservoir was improved. Figure 11c showed that the elevation of Chashma Reservoir for 10, 20 and 42 years of simulation for scenario 1 ranges between 604-634 ft. (184-193.24 m), 599-625 ft. (182.58-190.5 m) and 598-634 ft. (182.27-193.24 m) for section 1 and 614-639 ft.
(187.14-194.77 m), 599-635 ft. (182.57-193.55 m) and 604-634 ft. (184-193.24 m) for section 19. This showed that the elevation of Chashma Reservoir increases during 42 years of operation under existing conditions for future prediction of reservoir capacity. The results of scenario-1 showed that only $27 \%$ of gross storage capacity is left. Figure $11 \mathrm{~d}$ showed the elevation for scenario-II considering 15 days of flushing. The bed elevation of Chashma Reservoir after 42 years of operation decreased from 609 to $598 \mathrm{ft}$. (185.62-182.27 m) for section 1 and $614-604 \mathrm{ft}$. (187.14-184 m) for section 19. Figure 11e showed the elevation of Chashma Reservoir for 30 days flushing considering scenario-III. The elevation of points further decreased from 606 to $588 \mathrm{ft}$. (184.71-179.22 m) for section 1 and 616-595 (187.76-181.35 m) for section 19. Figure 11f showed the elevation for Chashma Reservoir for 45 days flushing decreased from 606 to $594 \mathrm{ft}$. (184.71-181.05 m) for section 1 and $611-600 \mathrm{ft}$. (186.23-182.88 m) for section 19 . Similarly, for scenario-V considering 60 days of flushing the elevation of points further decreased and ranges between 607 and $583 \mathrm{ft}$. (185-177.70 m) for section 1 and 617-604 ft. $(188-184 \mathrm{~m})$ for section 19 as shown in Fig. 11g. The figure showed the change in cross section of reservoir as per change in reservoir elevation. Furthermore, sediment movement towards the power channel increased which can cause negative impacts on long term power generation.

\section{Conclusions}

Following are the conclusions drawn from this study:

1. Average sedimentation rate in reservoir till 2012 is estimated as $0.0124 \mathrm{MAF} / \mathrm{year}(0.015 \mathrm{BCM} / \mathrm{year})$.

2. The storage capacity of Chashma Reservoir would deplete to 0.233 MAF ( $0.287 \mathrm{BCM})(73 \%$ loss) in the year 2054 for scenario-1 (under existing conditions).

3. Scenario-2 is more effective as $23 \%$ of reservoir capacity was recovered after 15 days of flushing and sediment trapped in the reservoir was lesser than the other flushing scenarios. The trap efficiency for Scenario-2 ranges between 43 and $11 \%$.

4. Depositional patterns in Chashma Reservoir showed that sediment movement towards the power channel increases. This would cause the negative effect on the power generation and also wear and tear of turbines. 
Fig. 11 Simulated bed profiles of Chashma Reservoir using various scenarios

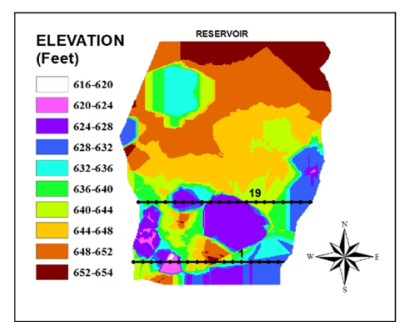

(A) Calibration (2008)
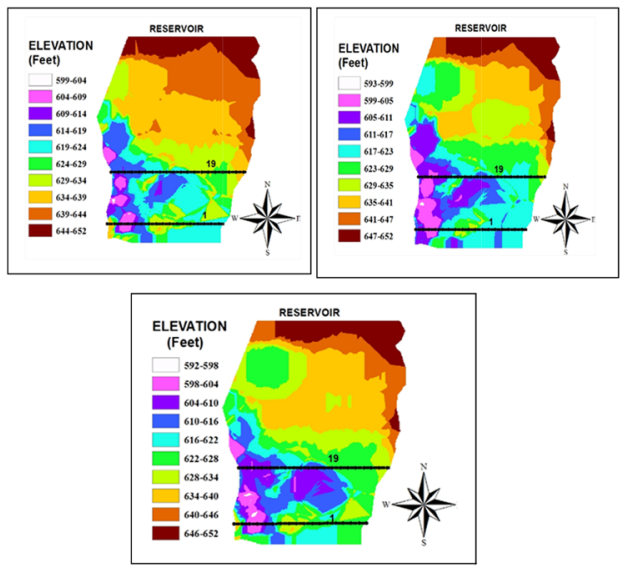

(C) Scenario-I
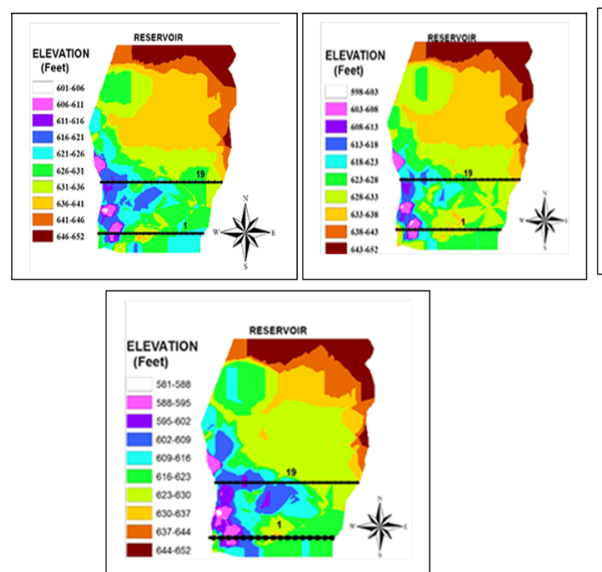

(E) Scenario-III

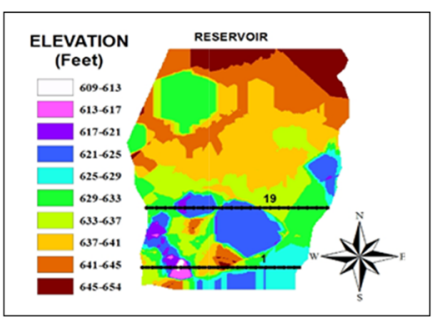

(B) Validation (20112)

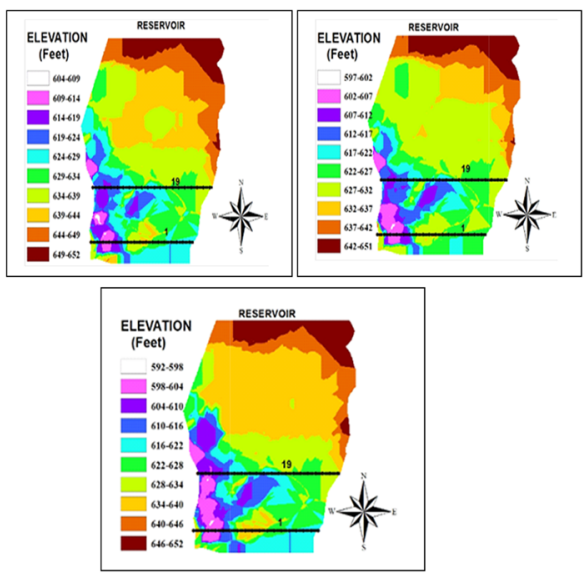

(D) Scenario-II

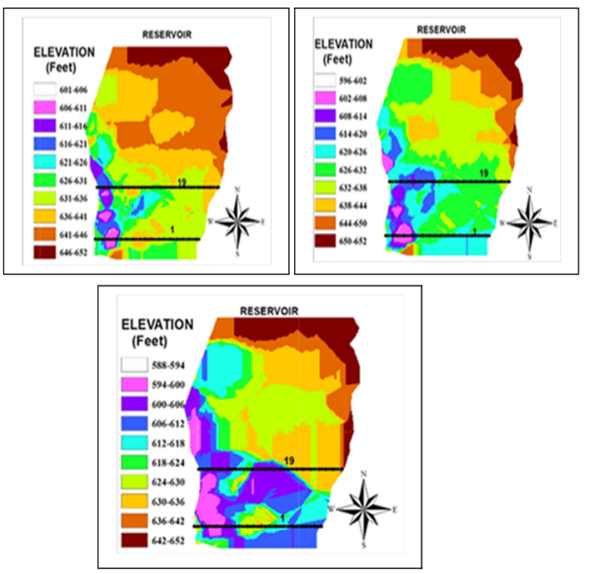

(F) Scenario-IV

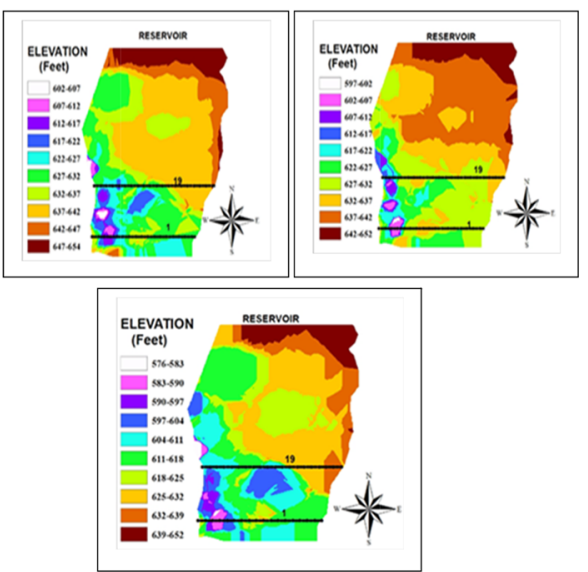

(G) Scenario-V 
Acknowledgements Authors are highly thankful to the SWHP (WAPDA) for providing inflows and sediment data and Mangla dam organization (MDO) for providing hydrographic surveys and reservoir levels. Furthermore, this research was made for partial fulfilment of M.Sc. thesis requirement.

Open Access This article is distributed under the terms of the Creative Commons Attribution 4.0 International License (http://creativeco mmons.org/licenses/by/4.0/), which permits unrestricted use, distribution, and reproduction in any medium, provided you give appropriate credit to the original author(s) and the source, provide a link to the Creative Commons license, and indicate if changes were made.

\section{References}

Basson GR (2009) Management of siltation in existing and new reservoirs. General Report, paper presented at the 23rd congress of the international commission on large dams, Int. Com. on Large Dams, Brasilia

Batuca DG, Jordaan JM Jr (2000) Silting and desilting of reservoirs. CRC Press, 1 Jan 2000
Mahmood K (1987) Reservoir sedimentation, impact, extent, and mitigation. World Bank technical paper no 71, Washington, DC, USA

Pakistan Water and Power Development Authority (2012) 5th Hydrographic survey of Chashma Reservoir. International Sedimentation Research Institute, Pakistan (ISRIP)

Schleiss A, De Cesare G, Althaus JJ (2010) Verlandung der Stauseen gef€ahrdet die nachhaltige Nutzung der Wasserkraft. Wasser Energ. Luft 102(1):31-40

Shah MU (2010) Assessment of Chashma Reservoir sedimentation using HEC-RAS. MSc thesis, University of Engineering and Technology, Lahore, p 148

White R (2001) Evacuation of sediments from reservoirs. Thomas Telford, London

Yang TC (2008) Applications of GSTARS computer models for solving river and reservoir sedimentation problems. Trans Tianjin Univ 14(4):235-247

Yang CT, Simoes FJM (2002) User's manual for GSTARS3 (Generalized sediment transport model for alluvial river simulation version 3.0). U.S. Bureau of Reclamation Technical Service Center, Denver, Colorado

Zeleke T, Moussa AM, El-Manadely MS (2013) Prediction of sediment inflows to Angereb dam reservoir using the SRH-1D sediment transport model. Lakes Reserv Res Manag 18(4):366-371. https ://doi.org/10.1111/lre.12047 